\title{
PERSPECTIVE
}

\section{A tale of two neurotransmitters}

\author{
DAVID W. MARSHAK \\ Department of Neurobiology and Anatomy, McGovern Medical School, University of Texas Health Science Center at Houston, \\ Houston, TX 77225
}

(RECEIVED September 29, 2016; ACCEPTED October 28, 2016)

\begin{abstract}
Amacrine cells are a diverse set of local circuit neurons of the inner retina, and they all release either GABA or glycine, amino acid neurotransmitters that are generally inhibitory. But some types of amacrine cells have another function besides inhibiting other neurons. One glycinergic amacrine cell, the Aii type, excites a subset of bipolar cells via extensive gap junctions while inhibiting others at chemical synapses. Many types of GABAergic amacrine cells also release monoamines, acetylcholine, or neuropeptides. There is now good evidence that another type of amacrine cell releases glycine at some of its synapses and releases the excitatory amino acid glutamate at others. The glutamatergic synapses are made onto a subset of retinal ganglion cells and amacrine cells and have the asymmetric postsynaptic densities characteristic of central excitatory synapses. The glycinergic synapses are made onto other types of ganglion cells and have the symmetric postsynaptic densities characteristic of central inhibitory synapses. These amacrine cells, which contain vesicular glutamate transporter 3, will be the focus of this brief review.
\end{abstract}

Keywords: GABA, Glycine, Amacrine, Vesicular glutamate transporter, Retina

\section{Introduction}

Vesicular glutamate transporters (vGluT) are a family of membrane proteins that transport glutamate from the cytoplasm into synaptic vesicles. The first members, vGluT1 and vGluT2, were identified based on their physiological activity. vGluT1 and vGluT2 are expressed by neurons in the brain that utilize glutamate as their primary neurotransmitter. Later, vGluT3 was identified based on the homology of its amino acid sequence with the other members of the family. vGluT3 is less abundant than the other vesicular glutamate transporters, and it is expressed in neurons that utilize other conventional neurotransmitters, including monoamines, acetylcholine, and amino acids (Fremeau et al., 2004). In the retina, the distribution of vesicular glutamate transporters is very similar. vGluT1 and vGlu2 are widely expressed by typical excitatory neurons, and vGluT3 is expressed by a small number of neurons that also release another conventional neurotransmitter. Rods, cones, and bipolar cells express vGluT1, and retinal ganglion cells express vGluT2 (Fujiyama et al., 2003; Johnson et al., 2003). In mammalian retinas, a single type of glycinergic amacrine cell expresses vGluT3 (Fremeau et al., 2002), and now there is good evidence that the two neurotransmitters are released at distinct synapses. In rat retinas, the vGluT3 cells comprise only $1 \%$ of all amacrine cells (Haverkamp \& Wassle, 2004), but several recent electrophysiological studies have shown that they play important roles in visual information processing. Their glycinergic synapses inhibit a subset

Address correspondence to: David W. Marshak, Ph.D., Department of Neurobiology and Anatomy, McGovern Medical School, PO Box 20708, Houston, TX 77225. E-mail: David.W.Marshak@uth.tmc.edu of cone bipolar cells and ganglion cells, and their glutamatergic synapses excite a subset of GABAergic amacrine cells and some other types of retinal ganglion cells.

\section{Morphology of vGluT3 amacrine cells}

The vGluT3 cells are a subtype of narrow-field amacrine cells, which have relatively small dendritic fields and branch in two or more of the five strata that comprise the inner plexiform layer (IPL). They typically use the neurotransmitter glycine and make inhibitory synapses onto bipolar cells, ganglion cells, and other amacrine cells. Several types of narrow-field amacrine cells have dendrites in both the inner strata of the IPL, where bipolar cells and ganglion cells that respond to increments in light intensity ramify, and in the outer strata of the IPL, where bipolar cells that respond to decrements in light intensity typically ramify (Wassle et al., 2009). The vGluT3 cells are bistratified, having dendrites that ramify in two relatively broad plexuses, one on either side of the center of the IPL. In primates, the plexus in the outer half of the IPL extends from approximately $20-40 \%$ of the IPL depth, and the plexus in the inner half extends from approximately $50-80 \%$, with $0 \%$ being the inner nuclear layer and $100 \%$ being the ganglion cell layer. The neurons that branch in these strata near the center of the IPL typically have relatively transient responses to light and are highly sensitive to moving and other rapidly changing stimuli (Marshak et al., 2015). In primates, these cells were previously identified based on their distinctive morphology, and they were named knotty bistratified type 1 cells (Mariani, 1990). These amacrine cells were called narrowfield bistratified in mice (Badea \& Nathans, 2004) and AB broad diffuse cells in rabbits (MacNeil et al., 1999). 


\section{Synaptic inputs to vGluT3 amacrine cells}

The vGluT3 amacrine cells receive excitatory synapses from bipolar cell axon terminals. In an electron microscopic immunolabeling study of rat retina, inputs from cone bipolar cells were seen in both the inner and outer halves of the IPL (Haverkamp \& Wassle, 2004). In electrophysiological studies of vGluT3 cells in mouse retina, glutamatergic, excitatory input is observed in response to both increments and decrements in light intensity, but the responses to decrements are larger (Lee et al., 2014; Kim et al., 2015). In a primate retina, on the other hand, inputs from bipolar cells are only detected in the inner half of the IPL, and excitatory inputs would be expected only at light onset (Marshak et al., 2015).

The majority of inputs to vGluT3 cells are inhibitory synapses from other amacrine cells. These include both GABAergic and glycinergic amacrine cells, but not vGluT3 cells, themselves (Lee et al., 2014). In primates, over $99 \%$ of the synapses onto vGluT3 cells are from other amacrine cells. ON-starburst cells may be among the presynaptic amacrine cells in S4. The large synapses from amacrine cells onto the primary dendrites of vGluT3 cells suggest that the entire cell might be inhibited under some conditions (Marshak et al., 2015). This input might originate from the dopaminergic cells, which have ON responses to light and inhibit multiple amacrine cell types via synapses onto their somas and primary dendrites (Debertin et al., 2015). In mouse retina, a major inhibitory input to the vGluT3 amacrine cells comes from spiking amacrine cells (Kim et al., 2015). Another presynaptic amacrine cell in mouse retina is the type two tyrosine hydroxylase-positive cell, a nonspiking GABAergic amacrine cell with $\mathrm{ON}-\mathrm{OFF}$ responses to light (Knop et al., 2011).

\section{Light responses of vGluT3 amacrine cells}

Light responses of identified vGluT3 cells have only been recorded from mouse retinas to date. With full-field stimuli, there is no response or else a small hyperpolarization. Voltage clamp studies under those conditions reveal a transient excitatory input that is amplified by voltage-gated sodium channels in the vGluT3 cells (Grimes et al., 2011). With a small spot of light in the receptive field center, the vGluT3 cells depolarize transiently at both at the onset and the offset; the OFF response is larger. However, they hyperpolarize at the onset and offset of a larger spot. This results from both a reduction in bipolar cell input to the vGluT3 cells and an enhancement of direct inhibition from amacrine cells (Lee et al., 2014). This very strong surround inhibition is consistent with the anatomical studies indicating a preponderance of amacrine cell input to vGluT3 cells. vGluT3 cells are also highly sensitive to movement. They depolarize in response to moving bars and gratings in the receptive field center, but they are inhibited when these stimuli extend into the receptive field surround. This response selectivity depends on input from spiking amacrine cells (Kim et al., 2015).

\section{Neurotransmitters of vGluT3 amacrine cells}

Fremeau et al. (2002) were the first to propose that vGluT3 cells in the retina released both glutamate and the inhibitory amino acid glycine, and this has now been confirmed by both anatomical and physiological studies. Electron microscopic immunolabeling experiments in baboon retina provided evidence suggesting that vGluT3 cells release glycine at some of their synapses and glutamate at others (Marshak et al., 2015). At synapses made by vGluT3 cells, some of the postsynaptic densities are relatively thin, as in symmetric synapses. At the other synapses made by vGluT3 cells, the postsynaptic densities were relatively thick, as in asymmetric synapses. These likely correspond to the rare, conventional synapses with E-face particles in the postsynaptic membrane that were observed in the macaque IPL in a study using freeze-fracture (Raviola \& Raviola, 1982). In the brain, symmetric synapses are known to be inhibitory and asymmetric synapses are known to be excitatory (Harris \& Weinberg, 2012).

Besides the presence of vGluT3, three lines of evidence indicate that these amacrine cells use glutamate as a neurotransmitter. The vGluT3 amacrine cells contain immunoreactive glutamate (Haverkamp \& Wassle, 2004), their dendrites are closely associated with puncta containing metabotropic glutamate receptor 4 (Johnson et al., 2004), and they make excitatory glutamatergic synapses onto several types of retinal ganglion cells (Lee et al., 2014; Krishnaswamy et al., 2015; Tien et al., 2016). There is good evidence that vGluT3 cells also use glycine as a neurotransmitter. They contain immunoreactive glycine (Haverkamp \& Wassle, 2004; Johnson et al., 2004), puncta containing the $\alpha 2$ subunit of the glycine receptor are found inside the presumed postsynaptic cells at appositions with dendrites of vGluT3 cells (Haverkamp et al., 2004; Jusuf et al., 2005; Knop et al., 2011), and they make glycinergic synapses onto mouse retinal ganglion cells whose responses are suppressed by stimulus contrast, also known as uniformity detectors (Lee et al., 2016; Tien et al., 2016).

\section{Postsynaptic targets of vGluT3 amacrine cells}

vGluT3 cells make synapses onto axon terminals of bipolar cells. In primates, vGluT3 cells make synapses onto OFF bipolar cells, including the DB3a type known to be presynaptic to parasol ganglion cells (Marshak et al., 2015). In mice, the vGluT3 cells make contacts with axons of type 3 and type 5 bipolar cells (Haverkamp \& Wassle, 2004). These two types of bipolar cells typically have transient responses to light (Euler et al., 2014). There is physiological evidence suggesting that the vGluT3 cells release glycine at their synapses onto ON bipolar cell axon terminals in mouse retina (Tien et al., 2016). In primates, approximately half of the output of vGluT3 cells is directed to other amacrine cells, and one of these, the Aii amacrine cell, was identified by light microscopy. The Aii amacrine cells are expected to be postsynaptic at the contacts with vGluT3 cells because Aii cells receive synapses from amacrine cells but do not make chemical synapses onto other amacrine cells (Wassle et al., 1995). ON starburst amacrine cells may also receive synapses from vGluT3 cells. Starburst cells are both presynaptic and postsynaptic to amacrine cells in macaque retina (Yamada et al., 2003), and, therefore, it is not possible to predict whether the vGluT3 cells or the starburst cells are presynaptic at their contacts (Marshak et al., 2015). In mice, there is physiological evidence suggesting that vGluT3 cells release glutamate at their synapses with unidentified GABAergic amacrine cells (Lee et al., 2014).

vGluT3 cells also make synapses onto dendrites of retinal ganglion cells (Fig. 1). In primates, approximately half of the synaptic output of vGluT3 cells is onto retinal ganglion cells. These include both ON and OFF subtypes of midget and parasol ganglion cells, and there is indirect evidence that at least some of these synapses are inhibitory (Marshak et al., 2015). In mice, vGluT3 cells release glutamate at synapses onto several types of retinal ganglion cells that are excited by stimulus contrast and motion. These include: $\mathrm{ON}$ direction selective, $\mathrm{ON}-\mathrm{OFF}$ direction selective, $\mathrm{W} 3 \mathrm{~B}$ and $\mathrm{OFF}$ 


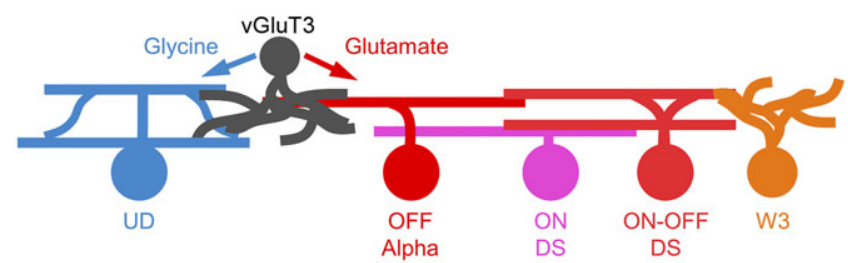

Suppressed-by-contrast

Enhanced-by-contrast

Fig. 1. Schematic diagram showing the effects of the vGluT3 cells (GAC) on various types of ganglion cells in mouse retina. These amacrine cells mediate glycinergic inhibition of the suppressed-by-contrast, also known as uniformity detectors (UD), types and glutamatergic excitation of several types whose responses are enhanced-by-contrast, including: OFF Alpha, ON and ON-OFF direction-selective (DSGC), and a subpopulation of W3 cells. Modified from Fig. 4G of Lee et al., (2016).

alpha cells. In general, the effects of the excitatory synapses from vGluT3 cells are to enhance the responses of each type to its characteristic trigger feature (Lee et al., 2014; Kim et al., 2015). Excitation from the vGluT3 is particularly important for the OFF component of the responses of W3B cells (Krishnaswamy et al., 2015). vGluT3 cells release glycine at synapses onto at least one other type of retinal ganglion cell, the spontaneously active cells whose responses are suppressed by stimulus contrast. These glycinergic synapses are one of four sources of inhibition to these ganglion cells, and they have a distinct contribution, namely inhibition at the offset of small stimuli (Lee et al., 2016; Tien et al., 2016). The ganglion cells that are suppressed by contrast are bistratified, and they receive the glycinergic synapses from vGluT3 cells on the dendrites connecting their two dendritic arbors, where the inhibition would be particularly effective (Tien et al., 2016).

\section{Contributions of vGluT3 cells to neural circuits in the retina}

In mouse retina, the amacrine cells containing vGluT3 have resting membrane potentials that are relatively depolarized, and therefore, they may release their neurotransmitters spontaneously (Grimes et al., 2011). This spontaneous activity might increase the sensitivity of vGluT3 cells and their postsynaptic targets to changes in illumination.

vGluT3 cells clearly impart selective sensitivity to small stimuli to their postsynaptic targets in the mouse retina. The specificity of the light responses of the vGluT3 cells closely resembles that of the glycinergic inhibitory input recorded from ganglion cells that are suppressed by contrast (Lee et al., 2016; Tien et al., 2016). The same is true of the mouse retinal ganglion cells that receive glutamatergic excitatory input from vGluT3 cells (Lee et al., 2014, 2016). In mice without vGluT3, excitation generated by selective stimulation in the receptive field center of W3B ganglion cells was greatly reduced, but excitation generated by other stimuli was unaffected (Kim et al., 2015). Because the signal passes through an additional neuron, the major excitatory input to W3B cells is slower than direct excitation via bipolar cells. The combination of rapid inhibition and slow excitation is thought to enhance the selectivity of W3B cells for object motion (Krishnaswamy et al., 2015).

Because the vGluT3 cells ramify in both the inner and outer sublaminae of the IPL, they are able to influence neurons with ON and neurons with OFF responses. The OFF responses of vGluT3 cells are the most prominent, and they might provide crossover inhibition to ON cells via their glycinergic synapses. Through their glutamatergic synapses, they could also provide crossover excitation, and this has been proposed as an explanation for the paradoxical ON responses of OFF ganglion cells under some conditions (Lee et al., 2014). Acting within a single sublamina, vGluT3 cells might provide either lateral inhibition or lateral excitation. Lateral excitation has been proposed as a mechanism to enhance synchronous firing of neighboring ganglion cells of the same type (Lee et al., 2014).

Another, more global function has also been proposed for the vGluT3 cells based on their actions in mouse retina. Glutamate released from vGluT3 cells excites ganglion cells that are highly sensitive to contrast and object motion. The same stimuli suppress the firing of ganglion cells that are inhibited by glycine released from the vGluT3 cells. The role proposed for vGluT3 cells is to coordinate signaling between the multiple parallel pathways in the inner retina. A single type of amacrine cell releasing both neurotransmitters simultaneously would, in theory, be able to accomplish this with much greater temporal precision than two distinct types (Lee et al., 2016; Tien et al., 2016). The same may also be true for other dual-neurotransmitter amacrine cells.

\section{Conclusions}

Many electrophysiological studies of synaptic inputs to neurons of the inner retina have utilized blockers of GABA and glycine receptors or else clamped the membrane voltage at the equilibrium potential for anions in order to study the inputs from bipolar cells. These experimental designs were based on the assumption that bipolar cells provide the only excitatory input to the IPL, but this is no longer true. It is clear now that vGluT3 amacrine cells release glutamate onto some of their postsynaptic targets. Under the conditions assumed to block amacrine cell input, the glutamatergic synapses of vGluT3 cells would still be active, and their effects would be interpreted, incorrectly, as originating from bipolar cells. Other possible sources of excitatory input are the monopolar neurons described recently in mouse retina (Della Santina et al., 2016) and the axon collaterals of melanopsin cells (Joo et al., 2013). Under physiological conditions, all three types of cells receive significant inhibitory input via GABA and glycine. When those inputs are blocked, the contributions of their excitatory synapses would appear much larger. These discoveries will also change the way electron micrographs of the neuropil are interpreted. Profiles in the IPL that make asymmetric synapses have always been assumed to originate from bipolar cell axon terminals, but they might also originate from amacrine cells containing vGluT3, monopolar cells or axon collaterals of intrinsically-photosensitive retinal ganglion cells.

\section{References}

Badea, T.C. \& Nathans, J. (2004). Quantitative analysis of neuronal morphologies in the mouse retina visualized by using a genetically directed reporter. Journal of Comparative Neurology 480, 331-351.

Debertin, G., Kantor, O., Kovacs-Oller, T., Balogh, L., SzaboMeleg, E., Orban, J., Nyitrai, M. \& Volgyi, B. (2015). Tyrosine hydroxylase positive perisomatic rings are formed around various amacrine cell types in the mammalian retina. Journal of Neurochemistry 134, 416-428.

Della Santina, L., Kuo, S.P., Yoshimatsu, T., OKawa, H., SuZuki, S.C., Hoon, M., Tsuboyama, K., Rieke, F. \& Wong, R.O. (2016). Glutamatergic monopolar interneurons provide a novel pathway of excitation in the mouse retina. Current Biology 26, 2070-2077.

Euler, T., Haverkamp, S., Schubert, T. \& Baden, T. (2014). Retinal bipolar cells: Elementary building blocks of vision. Nature Reviews Neuroscience 15, 507-519. 
Fremeau, R.T., Jr., Burman, J., Qureshi, T., Tran, C.H., Proctor, J., Johnson, J., Zhang, H., Sulzer, D., Copenhagen, D.R., StormMathisen, J., Reimer, R.J., Chaudhry, F.A. \& Edwards, R.H. (2002). The identification of vesicular glutamate transporter 3 suggests novel modes of signaling by glutamate. Proceedings of the National Academy of Sciences of the United States of America 99, 14488-14493.

Fremeau, R.T., Jr., Voglmaier, S., Seal, R.P. \& Edwards, R.H. (2004). VGLUTs define subsets of excitatory neurons and suggest novel roles for glutamate. Trends in Neurosciences 27, 98-103.

FujiYama, F., Hioki, H., TOMIOKa, R., TAKI, K., TAMAMAKI, N., NOMURA, S., Oкамото, K. \& KaneKo, T. (2003). Changes of immunocytochemical localization of vesicular glutamate transporters in the rat visual system after the retinofungal denervation. Journal of Comparative Neurology 465, 234-249.

Grimes, W.N., Seal, R.P., Oesch, N., Edwards, R.H. \& Diamond, J.S (2011). Genetic targeting and physiological features of VGLUT3+ amacrine cells. Visual Neuroscience 28, 381-392.

HARRIS, K.M. \& WeINBERG, R.J. (2012). Ultrastructure of synapses in the mammalian brain. Cold Spring Harbor Perspectives in Biology 4, 1-30.

Haverkamp, S., Muller, U., Zeilhofer, H.U., Harvey, R.J. \& Wassle, H. (2004). Diversity of glycine receptors in the mouse retina: Localization of the alpha2 subunit. Journal of Comparative Neurology 477, 399-411.

HAVERKAMP, S. \& WASSLE, H. (2004). Characterization of an amacrine cell type of the mammalian retina immunoreactive for vesicular glutamate transporter 3. Journal of Comparative Neurology 468, 251-263.

Johnson, J., Tian, N., Caywood, M.S., Reimer, R.J., Edwards, R.H. \& CoPENHAGEN, D.R. (2003). Vesicular neurotransmitter transporter expression in developing postnatal rodent retina: GABA and glycine precede glutamate. Journal of Neuroscience 23, 518-529.

Johnson, J., Sherry, D.M., Liu, X., Fremeau, R.T., Jr., Seal, R.P., EdWARDS, R.H. \& CoPEnhagen, D.R. (2004). Vesicular glutamate transporter 3 expression identifies glutamatergic amacrine cells in the rodent retina. The Journal of Comparative Neurology 477, 386-398.

Joo, H.R., Peterson, B.B., Dacey, D.M., Hattar, S. \& Chen, S.K. (2013). Recurrent axon collaterals of intrinsically photosensitive retinal ganglion cells. Visual Neuroscience 30, 175-182.

Jusuf, P.R., Haverkamp, S. \& Grunert, U. (2005). Localization of glycine receptor alpha subunits on bipolar and amacrine cells in primate retina. Journal of Comparative Neurology 488, 113-128.

Kim, T., Soto, F. \& Kerschensteiner, D. (2015). An excitatory amacrine cell detects object motion and provides feature-selective input to ganglion cells in the mouse retina. elife $\mathbf{4}$, e 08025 .
Knop, G.C., Feigenspan, A., Weiler, R. \& DedeK, K. (2011). Inputs underlying the ON-OFF light responses of type 2 wide-field amacrine cells in TH::GFP mice. Journal of Neuroscience 31, 4780-4791.

Krishnaswamy, A., Yamagata, M., Duan, X., Hong, Y.K. \& Sanes, J.R. (2015). Sidekick 2 directs formation of a retinal circuit that detects differential motion. Nature 524, 466-470.

Lee, S., Chen, L., Chen, M., Ye, M., Seal, R.P. \& Zhou, Z.J. (2014). An unconventional glutamatergic circuit in the retina formed by vGluT3 amacrine cells. Neuron 84, 708-715.

Lee, S., Zhang, Y., Chen, M. \& Zhou, Z.J. (2016). Segregated GlycineGlutamate Co-transmission from vGluT3 Amacrine Cells to ContrastSuppressed and Contrast-Enhanced Retinal Circuits. Neuron 90(1), 27-34

MacNeil, M.A., Heussy, J.K., Dacheux, R.F., Raviola, E. \& MasLAND, R.H. (1999). The shapes and numbers of amacrine cells: Matching of photofilled with golgi-stained cells in the rabbit retina and comparison with other mammalian species. Journal of Comparative Neurology 413, 305-326.

MARIANI, A.P. (1990). Amacrine cells of the rhesus monkey retina. Journal of Comparative Neurology 301, 382-400.

Marshak, D.W., Chuang, A.Z., Dolino, D.M., Jacoby, R.A., LiU, W.S. Long, Y.E., Sherman, M.B., SuH, J.M., Vila, A. \& Mills, S.L. (2015), Synaptic connections of amacrine cells containing vesicular glutamate transporter 3 in baboon retinas. Visual Neuroscience 32, E006.

Raviola, E. \& Raviola, G. (1982). Structure of the synaptic membranes in the inner plexiform layer of the retina: A freeze-fracture study in monkeys and rabbits. Journal of Comparative Neurology 209, 233-248.

Tien, N.W., Kim, T. \& Kerschensteiner, D. (2016). Target-specific glycinergic transmission from VGluT3-expressing amacrine cells shapes suppressive contrast responses in the retina. Cell Reports $\mathbf{1 5}$ $1369-1375$.

Wassle, H., Grunert, U., Chun, M.H. \& Boycott, B.B. (1995). The rod pathway of the macaque monkey retina: Identification of AII-amacrine cells with antibodies against calretinin. Journal of Comparative Neurology 361, 537-551.

Wassle, H., Heinze, L., Ivanova, E., Majumdar, S., Weiss, J., HARVEY, R.J. \& HAVERKAMP, S. (2009). Glycinergic transmission in the mammalian retina. Frontiers in Molecular Neuroscience 2, 6.

Yamada, E.S., Dmitrieva, N., Keyser, K.T., Lindstrom, J.M., Hersh, L.B. \& MarshaK, D.W. (2003). Synaptic connections of starburst amacrine cells and localization of acetylcholine receptors in primate retinas. Journal of Comparative Neurology 461, 76-90. 